\title{
Validity of a family-centered approach for assessing infants' social-emotional wellbeing and their developmental context: a prospective cohort study
}

\author{
Margriet Hielkema* ${ }^{*}$, Andrea F. De Winter and Sijmen A. Reijneveld
}

\begin{abstract}
Background: Family-centered care seems promising in preventive pediatrics, but evidence is lacking as to whether this type of care is also valid as a means to identify risks to infants' social-emotional development. We aimed to examine the validity of such a family-centered approach.

Methods: We conducted a prospective cohort study. During routine well-child visits (2-15 months), Preventive Child Healthcare (PCH) professionals used a family-centered approach, assessing domains as parents' competence, role of the partner, social support, barriers within the care-giving context, and child's wellbeing for 2976 children as protective, indistinct or a risk. If, based on the overall assessment (the families were labeled as "cases", $N=87$ ), an intervention was considered necessary, parents filled in validated questionnaires covering the aforementioned domains. These questionnaires served as gold standards. For each case, two controls, matched by child-age and gender, also filled in questionnaires $(N=172)$. We compared PCH professionals' assessments with the parent-reported gold standards. Moreover, we evaluated which domain mostly contributed to the overall assessment.

Results: Spearman's rank correlation coefficients between PCH professionals' assessments and gold standards were overall reasonable (Spearman's rho 0.17-0.39) except for the domain barriers within the care-giving context. Scores on gold standards were significantly higher when PCH assessments were rated as "at risk" (overall and per domain).We found reasonable to excellent agreement regarding the absence of risk factors (negative agreement rate: $0.40-0.98$ ), but lower agreement regarding the presence of risk factors (positive agreement rate: 0.00-0.67). An "at risk" assessment for the domain Barriers or life events within the care-giving context contributed most to being overall at risk, i.e. a case, odds ratio 100.1, 95\%-confidence interval: 22.6 - infinity.
\end{abstract}

Conclusion: Findings partially support the convergent validity of a family-centered approach in well-child care to assess infants' social-emotional wellbeing and their developmental context. Agreement was reasonable to excellent regarding protective factors, but lower regarding risk factors.

Trial registration: Netherlands Trialregister, NTR2681. Date of registration: 05-01-2011, URL: http://www.trialregister.nl/ trialreg/admin/rctview.asp?TC=2681.

Keywords: Family-centered care, Well-child care, Social-emotional development, Risk identification

\footnotetext{
*Correspondence: m.hielkema@umcg.nl

Department of Health Sciences, University Medical Center Groningen,

University of Groningen, Antonius Deusinglaan 1, 9713 AV Groningen,

Groningen, The Netherlands
} International License (http://creativecommons.org/licenses/by/4.0/), which permits unrestricted use, distribution, and reproduction in any medium, provided you give appropriate credit to the original author(s) and the source, provide a link to the Creative Commons license, and indicate if changes were made. The Creative Commons Public Domain Dedication waiver (http://creativecommons.org/publicdomain/zero/1.0/) applies to the data made available in this article, unless otherwise stated. 


\section{Background}

A child's development is influenced by the context in which it grows up, as well as by in addition to for example biological factors [1]. On the one hand, a positive and supportive context, as provided by adequate parenting, may optimize a child's development -within the possibilities of its genetic and biological make-up- [2, 3]. On the other hand, a less favorable context, as with marital conflict, maternal depression, or poverty, may have a negative influence $[4,5]$. The development of young children in particular is intertwined with their developmental context. The younger children are, the more they rely on their developmental context for the regulation of emotions and behavior [6].

Family-centered care may help to optimize a child's developmental context and in turn the child's socialemotional development [7], and has also been recognized as playing an important role in the quality of preventive pediatrics, as reflected by guidelines like Bright Futures of the American Academy of Pediatrics [8]. Table 1 presents the core principles of Familycentered care according to the American Academy of Pediatrics [9]. In the Netherlands, a family-centered approach, hereafter called the family-centered approach, has been introduced in Preventive Child Healthcare $(\mathrm{PCH})$ with, among others, the mandatory task of monitoring children's social-emotional development and their developmental context [10]. $\mathrm{PCH}$, like wellchild care in other countries, involves only preventive activities, and is offered free of charge to the total

Table 1 Core principles of family-centered care according to the American Academy of Pediatrics

\footnotetext{
1. Respecting each child and his or her family

2. Honoring racial, ethnic, cultural, and socioeconomic diversity and its effect on the family's experience and perception of care

3. Recognizing and building on the strengths of each child and family, even in difficult and challenging situations and respecting different methods of coping

4. Supporting and facilitating choice for the child and family about approaches to care and support

5. Ensuring flexibility in organizational policies, procedures, and provider practices so services can be tailored to the needs, beliefs, and cultural values of each child and family

6. Sharing honest and unbiased information with families on an ongoing basis and in ways they find useful and affirming

7. Providing and/or ensuring formal and informal support (eg, family-tofamily support) for the child and parent(s) and/or guardian(s) during pregnancy, childbirth, infancy, childhood, adolescence, and young adulthood

8. Collaborating with families at all levels of health care, in the care of the individual child and in professional education, policy making, and program development

9. Empowering each child and family to discover their own strengths, build confidence, and make choices and decisions about their health
}

Dutch population. More than $90 \%$ of all families with children frequently visit $\mathrm{PCH}$.

The newly implemented family-centered approach aims to build a trustful and supportive relationship with parents and to empower parenting skills, with the aim of enhancing children's developmental context. Next to these more general relational and participatory principles, the family-centered approach incorporates a systematic component, reflected by the use of a checklist to identify risk and protective factors for infants' socialemotional development [10]. Contents of the checklist are based on the bio-ecological model of Bronfenbrenner, which describes the factors that influence human development at different levels, taking into account both the child and its developmental context, and the interaction between the two [11]. In the family-centered approach, the bio-ecological model is reflected in the following domains related to children's social-emotional wellbeing: competence of the parent, role of the partner, social support, life events within the care giving context, and wellbeing of the child. Using the information on all domains, $\mathrm{PCH}$ professionals draw an overall conclusion about the child's socialemotional wellbeing.

The family-centered approach seems promising for preventive pediatrics. However, evidence is lacking as to whether this approach allows for valid assessment of protective and risk factors regarding infants' social-emotional development in well-child care. Therefore, the aim of this study was to examine this validity, and to compare the agreement between $\mathrm{PCH}$ professional's assessments and parents' responses in validated questionnaires.

\section{Methods}

The current study was part of a large quasi-experimental study comparing the family-centered approach with careas-usual in Dutch PCH. For the current study, we used data only of participants fully offered the family-centered approach in order to make an adequate assessment of its performance. The study was approved by the Medical Ethics Committee of the University Medical Center Groningen. Below, we summarize its design; further details have been described in a separate design paper [12].

\section{Participants}

We used data from a cohort of 2976 participants in the family-centered condition who gave written informed consent at the start of the study, when their child was about 2 months old. When they consented, parents were informed that they could be asked to participate in an extra interview when $\mathrm{PCH}$ professionals provided any extra care for the infants' social-emotional development. Of the 2976 participants, 114 were asked by $\mathrm{PCH}$ professionals, i.e. nurses and medical doctors, to participate in such interviews because of the need for an additional 
activity regarding the child's social-emotional development (e.g., an additional phone call, appointment or extra well-child visit to assess the situation more in depth, or an intervention like a referral to a child psychologist); 87 parents (76\%) agreed on this. Three families were seen twice and two families three times, because more than once during the period from 2 to 18 months an additional activity from $\mathrm{PCH}$ was needed. For the analysis, we took into account only the first identification of each family. For all cases, two "control" families, matched by age and gender of the child, but for whom $\mathrm{PCH}$ performed no additional activity, were invited. Of 2 of the 174 controls, data could not be used because their medical records did not include data regarding the family-centered approach.

\section{Intervention and procedures}

The family-centered approach is the only approach in Dutch $\mathrm{PCH}$ that takes into account the child within its context and can be used during all routine well-child visits from birth onwards. The family-centered approach strongly focuses on building rapport with parents. Where possible, $\mathrm{PCH}$ professionals attune their care to the needs and wishes of each family by taking the parents' (or caregivers') point of view as basis for the well-child visit and treating them as equal partners and experts on their child [13]. Through empowering communication, $\mathrm{PCH}$ professionals aim to enhance parents' confidence and parenting skills, thereby trying to improve the child's developmental context. Next to these more general principles, the approach consists of a checklist that covers five domains associated with children's social-emotional development (see Additional file 1: Appendix 1 for the domains and questions regarding these domains) [10]. The questions for each domain form a guideline for $\mathrm{PCH}$ professionals for their conversation with parents. The professionals used the familycentered approach during each routine well-child visit for children aged 2, 3, 4, 6, 7,5, 9, 11, and 14 months. For each domain, $\mathrm{PCH}$ professionals registered information within the child's medical record as not discussed, protective, indistinct, or at risk. The term protective reflected either a stable or enhancing situation for both high- and low-risk children, conform the use of promotive factors as previously described by Sameroff [14]; indistinct reflected a situation that could not correctly be labeled either as protective nor at risk. Subsequently an explanation in free text could be provided. Based on the appraisal of all the domains, the parent and the $\mathrm{PCH}$ professional jointly decided whether there were any causes for concern, and an overall conclusion was drawn as fine, not optimal or a problem. In cases of concern, an additional activity aimed at the social-emotional development of the child was planned, for example an additional appointment to assess the situation more in depth or an intervention like a referral to a child psychologist.

All $\mathrm{PCH}$ professionals attended 4 days of training before starting with the family-centered approach. Within one month after training they had to videotape two wellchild visits in which they used the family-centered approach. The videos were discussed with trainers who used standardized guidelines to determine the adequacy of trainees' performance [10]. This procedure was repeated until the performance of the family-centered approach was rated as adequate. Furthermore, the $\mathrm{PCH}$ professionals attended supervision every three months. Before our study started, we trained all these professionals for half a day, providing practical as well as theoretical information on the study as, for example, how to include participants and how to provide cases for the study.

All cases and controls were contacted by trained interviewers from the research institute for a questionnairebased interview at the parents' home (see Table 2 for all the questionnaires used), five families preferred filling in the questionnaire themselves and were mailed. Whenever feasible, appointments were made within one week after the routine well-child visit, this was possible for $53 \%$ of the interviews. In case of intervals longer than one week, we checked with $\mathrm{PCH}$ professionals about possible changes in the situation during the time between the well-child visit and the interview. Families participated in the interview only if no relevant changes had taken place since the last well-child visit.

\section{Measures}

$\mathrm{PCH}$ professionals assessed all five domains of the family-centered approach by using the questions in the checklist (see Additional file 1: Appendix). They evaluated information on these domains as not discussed, protective, indistinct, or at risk and subsequently rated the overall situation as fine, not optimal or a problem, as described under the heading of "Procedures". By means of an interview, parents filled out questionnaires with good construct and/or criterion validity. These questionnaires served as gold standard for the domains of the familycentered approach. The questionnaires are shown in Table 2.

If for controls specific ratings for domains or the overall conclusion were missing, those from the subsequent visit were used. This was done only when that rating contained a note stating that nothing had changed since the previous visit. Furthermore, in the case of missing ratings on domains for both controls and cases, we coded domains as protective if free text explicitly stated that everything was fine and as indistinct when free text stated that problems or barriers existed. For 44 controls 
Table 2 Parent-report questionnaires used as gold standards for the domains of the family-centered care approach

\begin{tabular}{|c|c|c|c|c|c|c|}
\hline $\begin{array}{l}\text { Domain of the } \\
\text { Family-centered } \\
\text { approach }\end{array}$ & Criterion & $\begin{array}{l}\text { Nr. of } \\
\text { items }\end{array}$ & Measuring & $\begin{array}{l}\text { Information on reliability and } \\
\text { validity (and Cronbach's alpha } \\
\text { in our study) }\end{array}$ & $\begin{array}{l}\text { Cut-off } \\
\text { scores }\end{array}$ & References \\
\hline $\begin{array}{l}\text { Wellbeing of the } \\
\text { child }\end{array}$ & $\begin{array}{l}\text { Ages and Stages } \\
\text { Questionnaire Social } \\
\text { Emotional (ASQ-SE) } \\
\text { (versions } 6,12 \text { and } \\
18 \text { months) }\end{array}$ & $22-29$ & $\begin{array}{l}\text { Social-emotional } \\
\text { development of } \\
\text { the child }\end{array}$ & $\begin{array}{l}\text { Cronbach's alpha } 0.82 \text {. Test-retest } \\
\text { reliability } 0.94 \text {. Sensitivity } 0.75-0.89 \text {. } \\
\text { Specificity } 0.82-0.96 \text {. } \\
(0.41-0.69)\end{array}$ & High $>2$ sd & [27] \\
\hline \multirow[t]{4}{*}{$\begin{array}{l}\text { Competence of } \\
\text { the parent }\end{array}$} & $\begin{array}{l}\text { Dutch Parenting Stress } \\
\text { Index (PSI) (4 subscales) }\end{array}$ & 11 & $\begin{array}{l}\text { Parental competence } \\
\text { and attachment }\end{array}$ & $\begin{array}{l}\text { Cronbach's alpha } 0.92-0.96 . \\
\text { Good construct and criterion } \\
\text { validity* } \\
(0.82)\end{array}$ & $\begin{array}{l}\text { High }>90 \text { th } \\
\text { pct }\end{array}$ & [28] \\
\hline & $\begin{array}{l}\text { Parenting Tasks Checklist } \\
\text { or Problem Setting and } \\
\text { Behavior Checklist } \\
\text { (PSBC)(Setting Self-Efficacy } \\
\text { subscale) }\end{array}$ & 14 & $\begin{array}{l}\text { Perceived ability of } \\
\text { the primary caretaker } \\
\text { in mastering problem } \\
\text { situations }\end{array}$ & $\begin{array}{l}\text { Cronbach's alpha } 0.91 \\
(0.89)\end{array}$ & $\begin{array}{l}\text { Low }<10 \text { th } \\
\text { pct }\end{array}$ & [29] \\
\hline & $\begin{array}{l}\text { Parental Sense of } \\
\text { Competence scale } \\
\text { (PSOC) }\end{array}$ & 16 & $\begin{array}{l}\text { Competence of the } \\
\text { parent }\end{array}$ & $\begin{array}{l}\text { Cronbach's alpha } 0.70-0.88 \text {. } \\
\text { Test-retest reliability } 0.46-0.82 \text {. } \\
\text { Good construct validity. } \\
(0.84)\end{array}$ & High: >2 sd & [30] \\
\hline & $\begin{array}{l}\text { SF-12 Health Survey } \\
\text { SF-12 mental } \\
\text { SF-12 physical }\end{array}$ & 12 & $\begin{array}{l}\text { Health status (physical } \\
\text { and mental) of the } \\
\text { parent }\end{array}$ & $\begin{array}{l}\text { Abbreviated version of the } \\
\text { validated } 36 \text {-Item Short Form } \\
\text { Health Survey. Correlations } \\
\text { betwee SF- } 36 \text { and SF-12 are } \\
\text { high, i.e. } 0.94-0.97 \\
(0.67-0.71)\end{array}$ & $\begin{array}{l}\text { Low: }<10 \text { th } \\
\text { pct } \\
\text { Low: }<10 \text { th } \\
\text { pct }\end{array}$ & [31] \\
\hline \multirow[t]{2}{*}{ Role of the partner } & $\begin{array}{l}\text { McMaster Family } \\
\text { Assessment Device } \\
\text { (FAD) (General } \\
\text { Functioning subscale) }\end{array}$ & 12 & $\begin{array}{l}\text { Emotional relationships } \\
\text { within families }\end{array}$ & $\begin{array}{l}\text { Cronbach's alpha } 0.66-0.81 . \\
\text { Good construct validity. } \\
(0.94)\end{array}$ & $\begin{array}{l}\text { High: >90th } \\
\text { pct }\end{array}$ & [32] \\
\hline & $\begin{array}{l}\text { Dutch Parental } \\
\text { Stress Index (PSI) } \\
\text { (subscale partner) }\end{array}$ & 5 & $\begin{array}{l}\text { Having a child and } \\
\text { its effect on the } \\
\text { relationship between } \\
\text { partners }\end{array}$ & $\begin{array}{l}\text { Cronbach's alpha } \\
0.92-0.96 \text {. Good } \\
\text { construct and criterion } \\
\text { validity* }(0.71)\end{array}$ & $\begin{array}{l}\text { High: >90th } \\
\text { pct }\end{array}$ & [28] \\
\hline \multirow[t]{2}{*}{ Social support } & $\begin{array}{l}\text { Social Support List, } \\
\text { short version }(S S L) \\
\text { Received } \\
\text { Shortage }\end{array}$ & 12 & Social support & $\begin{array}{l}\text { Cronbach's alpha } 0.69-0.96, \\
\text { Construct and criterion } \\
\text { validity sufficient* } \\
(0.74-0.79)\end{array}$ & $\begin{array}{l}\text { Low: }<2 \text { sd } \\
\text { High: }>90 \text { th } \\
\text { pct }\end{array}$ & [33] \\
\hline & $\begin{array}{l}\text { Loneliness-score } \\
\text { Social } \\
\text { Emotional }\end{array}$ & 11 & $\begin{array}{l}\text { Feelings of overall, } \\
\text { emotional and social } \\
\text { loneliness }\end{array}$ & $\begin{array}{l}\text { Cronbach's alpha } 0.80-0.90 \text {. } \\
\text { sufficient content validity. } \\
(0.80-0.85)\end{array}$ & $\begin{array}{l}\text { High: >90th } \\
\text { pct } \\
\text { High: > 90th } \\
\text { pct } \\
\text { High: >90th } \\
\text { pct }\end{array}$ & [34] \\
\hline \multirow[t]{2}{*}{$\begin{array}{l}\text { Perceived barriers or } \\
\text { life events within } \\
\text { the care giving context } \\
\text { of the child }\end{array}$} & $\begin{array}{l}\text { Questionnaire on the } \\
\text { material or social } \\
\text { deprivation of a child } \\
\text { due to shortage } \\
\text { of money (deprivation } \\
\text { questionnaire) }\end{array}$ & 15 & $\begin{array}{l}\text { The material or social } \\
\text { deprivation of a child } \\
\text { due to shortage of } \\
\text { money }\end{array}$ & $\begin{array}{l}\text { Cronbach's alpha } 0.89 . \\
(0.63)\end{array}$ & $\begin{array}{l}\text { High: > 90th } \\
\text { pct }\end{array}$ & [35] \\
\hline & $\begin{array}{l}\text { Dutch Parental } \\
\text { Stress Index (PSI) } \\
\text { (subscale life events) }\end{array}$ & 17 & $\begin{array}{l}\text { Life events happened } \\
\text { in the past year }\end{array}$ & $\begin{array}{l}\text { Cronbach's alpha } 0.92-0.96 \text {. } \\
\text { Good construct and criterion } \\
\text { validity* }\end{array}$ & High: >2 sd & [28] \\
\hline
\end{tabular}

Sd: standard deviation

Pct: percentile

and 15 cases we coded one or more domains as so described.

Moreover, we assessed the following background characteristics of parents: age, educational level, working participation, country of birth and furthermore the family composition, and having one or more children. We used this information from the child's medical record or, if records lacked data on this, from the parent reported questionnaire at the start of our study. Educational level reflected the highest obtained level for one of both 
parents and was divided into low (primary school or less, lower vocational or lower general secondary education), medium (intermediate vocational education, intermediate or higher secondary education) and high (higher vocational education or university).

\section{Analysis}

Analyses were performed using the Statistical Package for Social Sciences (SPSS) version 20. The statistical significance level was set at.05. We first compared background characteristics of cases and controls by using Chi-square tests or Fisher's exact tests in case of more than $20 \%$ of cells with an expected count $<5$.

Second, we assessed the convergent validity by computing Spearman's rank correlation coefficients between $\mathrm{PCH}$ professionals' assessments (protective, indistinct or at risk) and the gold standards for the domains of the family-centered approach. Correlation coefficients $>.30$ were interpreted as reasonable [15]. Additionally, we compared scores on the gold standards for cases versus controls, i.e. $\mathrm{PCH}$-initiated intervention versus no intervention, and per domain (assessed as at risk versus assessed as not at risk) using conditional logistic regression analysis to take into account the matching by age and gender [16]. Effect sizes were then computed [16], effect sizes from $0.10-0.30$ were interpreted as small, $0.30-0.50$ as medium and $>0.50$ as large [17].

Third, we assessed the agreement between $\mathrm{PCH}$ professionals' assessments and the gold standards regarding the domains of the family-centered approach. We calculated percentages of agreement overall, and for cases and controls separately using the mean of $(\mathrm{P}(\mathrm{PCH}$ professional's assessment risk/ gold standard risk $)+\mathrm{P}(\mathrm{PCH}$ professional's assessment protective/ gold standard protective)). Furthermore, for a better understanding of our results, we calculated both the positive agreement (Ppos), i.e. the agreement regarding the presence of risk factors, and negative agreement (Pneg), i.e. the agreement on the absence of risk factors [18]. For this purpose we dichotomized the scores of $\mathrm{PCH}$ professionals' assessments as protective versus indistinct or at risk per domain, and divided questionnaire scores into low and high scores. We based this latter dichotomization on the scores of controls; high scores were defined as more than two standard deviations higher than the mean, or, in case of skewed data, as higher than the 90th percentile. Whenever norm scores were available for a questionnaire, we also used these to dichotomize our data based.

Finally, we assessed which domains contributed most to $\mathrm{PCH}$ professionals' overall assessments by calculating the percentages of risk assessments per domain for both cases and controls and performing conditional univariate logistic regression analysis to show to what extent each domain separately contributed to the overall conclusion of the $\mathrm{PCH}$ professional as to whether or not a child was at risk.

\section{Results}

Background characteristics of both cases and controls are presented in Table 3. Regarding cases, mothers were more often below 20 years or over 40 years of age. Moreover, cases more often came from a one-parent household.

\section{Convergent validity}

Table 4 shows Spearman's rank correlations between domains rated as protective versus indistinct or at risk and scores on the related questionnaires. All correlations were statistically significant (ranging from .17 to .39 with around two third >.30) and highest for the domains that the questionnaire should cover, except for the PSBC, the Loneliness score Emotional and the Deprivation Questionnaire.

Scores on the parent-reported questionnaires were mostly higher for children for whom $\mathrm{PCH}$ professionals initiated an intervention (cases) than for children for whom they did not so (controls); see mean scores in Table 4. Effect sizes ranged from marginal to medium. We found similar effect sizes for the PCH professionals' conclusions per domain protective versus indistinct or at risk.

\section{Agreement between PCH professionals and parents per domain}

Table 5 shows findings regarding agreement between $\mathrm{PCH}$ professionals and parents per domain, for cases and controls separately and combined. We found reasonable to excellent levels of agreement (61\%-98\%). Overall we found higher agreement for cases than for controls, especially for the domains Social support and Perceived barriers or life events within the care giving context (agreement between 63\%-85\% versus 46\%-59\% for cases and controls respectively). For the domain Wellbeing of the child, the agreement for controls was higher than for cases (98\% versus 67\%). The agreement on the absence of risk factors (Pneg), which in this study indicated the presence of protective factors (see "intervention and procedures"), was overall satisfactory, and was especially high for controls. The agreement on the presence of risk factors (Ppos) was low (lowest for controls). For cases, $\mathrm{PCH}$ professionals frequently identified a risk where parents scored low on the accompanying questionnaires whereas the discrepancy 'professional: protective'; 'parent: risk' occurred more frequently among controls.

\section{Contribution of domains to the PCH professional's overall assessmen}

Table 6 shows the rates of at risk and protective factors per domain that $\mathrm{PCH}$ professionals assessed, for cases versus controls, and the results of the univariate logistic regression analyses. The domain Barriers or life events 
Table 3 Background characteristics of participants

\begin{tabular}{|c|c|c|c|c|}
\hline & $\begin{array}{l}\text { Cases } \\
(N=87)\end{array}$ & $\begin{array}{l}\text { Controls } \\
(N=172)\end{array}$ & $\begin{array}{l}\text { Total cohort } \\
(N=2835)\end{array}$ & $\begin{array}{l}P \text {-value } \\
\text { cases-controls }{ }^{\phi} / \text { cases-total cohort }\end{array}$ \\
\hline \multicolumn{5}{|l|}{ Gender } \\
\hline Male & $46(52.9 \%)$ & $90(52.3 \%)$ & $1420(50.1 \%)$ & \\
\hline Female & $41(47.1 \%)$ & $82(47.7 \%)$ & 1414 (49.9\%) & .61 \\
\hline \multicolumn{5}{|l|}{ Highest educational level of either parents } \\
\hline Lower & $4(4.8 \%)$ & $4(2.4 \%)$ & $119(4.7 \%)$ & .06 \\
\hline Secondary & $44(57.9 \%)$ & 77 (45.6\%) & 1099 (43.0\%) & .03 \\
\hline Higher & $28(36.8 \%)$ & $88(52.1 \%)$ & $1336(52.3 \%)$ & \\
\hline \multicolumn{5}{|l|}{ Parental age } \\
\hline \multicolumn{5}{|l|}{ Mother } \\
\hline Younger than 20 & $2(2.3 \%)$ & $1(0.6 \%)$ & $15(0.6 \%)$ & $.04^{\mathrm{a}}$ \\
\hline $20-40$ & 81 (93.1\%) & $169(98.8 \%)$ & $2351(96.6 \%)$ & $.05^{\mathrm{a}}$ \\
\hline 40 years and over & $4(4.6 \%)$ & $1(0.6 \%)$ & $59(2.4 \%)$ & \\
\hline \multicolumn{5}{|l|}{ Father } \\
\hline Younger than 20 & $1(1.2 \%)$ & $1(0.6 \%)$ & $5(0.2 \%)$ & $.73^{\mathrm{a}}$ \\
\hline $20-40$ & $70(81.4 \%)$ & $141(84.9 \%)$ & $2092(89.6 \%)$ & .03 \\
\hline 40 years and over & $15(17.4 \%)$ & $24(14.5 \%)$ & $239(10.2 \%)$ & \\
\hline \multicolumn{5}{|l|}{ Employment status parent } \\
\hline One of both or both parents have & $85(97.7 \%)$ & $167(97.7 \%)$ & $1206(94.4 \%)$ & $1.00^{\mathrm{a}}$ \\
\hline paid work & & & & $.23^{\mathrm{a}}$ \\
\hline None of both parents has paid & $2(2.3 \%)$ & $4(2.3 \%)$ & $72(5.6 \%)$ & \\
\hline \multicolumn{5}{|l|}{ Work } \\
\hline \multicolumn{5}{|l|}{ Country of birth parent } \\
\hline One or both born in the Netherlands & $86(98.9 \%)$ & $169(100.0 \%)$ & $2460(99.3 \%)$ & $.34^{\mathrm{a}}$ \\
\hline Both born outside the Netherlands & $1(1.1 \%)$ & $0(0.0 \%)$ & $86(0.7 \%)$ & $.48^{\mathrm{a}}$ \\
\hline \multicolumn{5}{|l|}{ Family composition } \\
\hline Two parents household & $78(91.1 \%)$ & $171(99.4 \%)$ & 2046 (96.9\%) & $.01^{\mathrm{a}}$ \\
\hline One parent household & $7(8.2 \%)$ & $1(0.6 \%)$ & $65(3.1 \%)$ & $.05^{\mathrm{a}}$ \\
\hline \multicolumn{5}{|l|}{ Number of children } \\
\hline First child & $37(43.4 \%)$ & $81(47.1 \%)$ & 1215 (42.9\%) & .59 \\
\hline More children & $48(56.5 \%)$ & $91(52.9 \%)$ & $1620(55.3 \%)$ & 1.00 \\
\hline
\end{tabular}

abased on Fisher's exact test

b participants for whom data was available, cases excluded

$\phi_{\text {for }}$ gender the $p$-value was not given for the comparison between cases and controls because of the matching by gender

within the care-giving context contributed the most to the overall assessment; if this domain was assessed as at risk, participants had an odds of about 100 to be assessed as a case, compared to when this domain was assessed as protective. Furthermore, when participants had two or more risk factors, they had a higher odds of being assessed as a case (odds ratio: 79.8; 95\% confidence interval: 27.0-236.3).

\section{Discussion}

In this study we examined the validity of a familycentered approach in well-child care for the early identification of concerns regarding infants' social-emotional development. Results showed that $\mathrm{PCH}$ professionals' assessments of infants' social-emotional wellbeing and their developmental context, based on a family-centered approach, were associated with scores on gold standards. The agreement between $\mathrm{PCH}$ and parents per domain was overall satisfactory to excellent for protective factors, but not for risk factors. The domain Barriers or life events within the care-giving context contributed most to the $\mathrm{PCH}$ professional's overall assessment of being at risk.

Our study was the first to assess extensively the validity of a family-centered approach, and our findings partially support its validity. These findings correspond with previous ones on the validity of this specific approach 
Table 4 Comparison of scores on parent-reported questionnaires (i.e. gold standards) between cases and controls

\begin{tabular}{|c|c|c|c|c|c|c|c|c|c|}
\hline & \multicolumn{3}{|c|}{$\begin{array}{l}\text { Cases (intervention based } \\
\text { on overall assessment) }\end{array}$} & \multicolumn{3}{|c|}{$\begin{array}{l}\text { Controls (no intervention based } \\
\text { on overall assessment) }\end{array}$} & \multirow[b]{2}{*}{$P$-value } & \multirow[b]{2}{*}{ Effect size Cohen's d } & \multirow[b]{2}{*}{ Spearman's rho } \\
\hline & $N$ & Mean & (sd) & $N$ & Mean & (sd) & & & \\
\hline \multicolumn{10}{|l|}{ Wellbeing of the child } \\
\hline ASQ-SE & 84 & $0.41^{\mathrm{a}}$ & $(1.1)$ & 165 & $-0.21^{a}$ & $(.84)$ & $<.001$ & .33 & $.306^{* * *}$ \\
\hline \multicolumn{10}{|l|}{ Competence of the parent } \\
\hline PSI & 86 & 23.4 & (8.9) & 169 & 18.3 & $(5.4)$ & $<.001$ & .06 & $.322^{* * *}$ \\
\hline PSOC & 85 & 36.6 & $(10.9)$ & 167 & 30.2 & $(7.2)$ & $<.001$ & .30 & $.269^{* * *}$ \\
\hline PSBC ${ }^{b}$ & 87 & 8.8 & $(1.0)$ & 172 & 9.2 & $(0.8)$ & .001 & .04 & $-.208^{* * * c}$ \\
\hline SF-12 mental ${ }^{\mathrm{b}}$ & 87 & 44.2 & $(11.1)$ & 172 & 52.9 & (7.8) & $<.001$ & .05 & $-.371^{* * *}$ \\
\hline SF-12 physical $^{b}$ & 87 & 49.5 & (8.6) & 172 & 50.5 & $(8.2)$ & .45 & .01 & $-.169^{* * *}$ \\
\hline \multicolumn{10}{|l|}{ Partner } \\
\hline FAD & 82 & 21.2 & $(10.0)$ & 167 & 15.3 & (3.6) & $<.001$ & .10 & $.394^{* * *}$ \\
\hline PSI (partner) & 79 & 9.6 & (3.2) & 172 & 7.7 & $(2.4)$ & $<.001$ & .16 & $.269^{* * *}$ \\
\hline \multicolumn{10}{|l|}{ Social support } \\
\hline SSL received ${ }^{b}$ & 87 & 15.2 & (3.1) & 172 & 15.7 & $(2.8)$ & .17 & .03 & $-.231^{* * *}$ \\
\hline SSL shortage & 86 & 8.4 & (3.1) & 172 & 6.8 & (1.3) & $<.001$ & .23 & $.375^{* * *}$ \\
\hline Loneliness score & 87 & 2.7 & (3.0) & 172 & 1.1 & (1.9) & $<.001$ & .17 & $.293^{* * *}$ \\
\hline Social & 87 & 1.1 & $(1.5)$ & 172 & 0.6 & $(1.0)$ & .002 & .20 & $.375^{* * *}$ \\
\hline Emotional & 87 & 1.6 & (1.8) & 172 & 0.5 & $(1.2)$ & $<.001$ & .28 & $.394^{* * * c}$ \\
\hline \multicolumn{10}{|c|}{ Barriers or life events within care-giving context } \\
\hline Deprivation Questionnaire & 86 & 0.5 & (1.4) & 171 & 0.1 & $(0.3)$ & .004 & .49 & $.272^{* * * c}$ \\
\hline PSI (life events) & 87 & 1.5 & $(1.0)$ & 172 & 1.3 & $(1.0)$ & .08 & .13 & $.212^{* *}$ \\
\hline
\end{tabular}

${ }^{\mathrm{a}}$ Based on Z-scores

${ }^{b}$ Lower scores reflect worse outcomes

'Spearman's rho was higher between the questionnaire scores and one of the other domains than with the intended corresponding domain

${ }^{* *} p$-value $<.05$

*** $p$-value $<.01$

[10], and with findings on a similar approach, the Structured Problem Analysis of Raising Kids (SPARK), which also showed only partial support for the validity [19]. However, as our study covered more areas than only child development, family stress and family needs, it is difficult to make a comprehensive comparison of all findings.

We found that the agreement on protective factors was satisfactory to very good, especially for controls, but this was not always the case with risk factors. This finding suggests that the family-centered approach does not enable $\mathrm{PCH}$ professionals fully to assess risk factors. This is in line with previous findings of suboptimal identification by $\mathrm{PCH}$ regarding risk factors such as child abuse and psychosocial problems [20, 21]. Reasons for a suboptimal identification of risk factors could be the limited amount of time during well-child visits [22], or insufficient training to detect social-emotional problems. Moreover, identification of social-emotional problems in infants may also be more difficult [23].

Alternatively, the lower agreement regarding risk factors compared to protective factors may also reflect daily practice. First, with regard to cases, $\mathrm{PCH}$ professionals frequently assessed risk factors, whereas parents did not (yet). This may be the result of the preventive task of $\mathrm{PCH}$ and the family-centered approach, i.e. aiming to identify risks at an early stage to prevent (worsening of) problems whenever possible. The focus on risk factors may, however, entail the risk of stigmatization, and might interfere with the parental empowering advocated in the family-centered approach [10].

Second, $\mathrm{PCH}$ professionals also registered protective factors in some instances where parents scored high on the accompanying questionnaires, especially for controls. This may be because professionals take into account both protective and risk factors and are aware that protective factors can counterbalance risk factors. On the other hand, it may also be that professionals are reluctant to discuss certain topics with parents and tend to rate domains as protective, or that parents may be reluctant to discuss their worries or problems with $\mathrm{PCH}$ professionals. This issue evidently requires further study. If reluctance of parents to discuss is the issue, then more 
Table 5 Agreement between assessments of PCH professionals and scores on parent-reported gold standards per domain

\begin{tabular}{|c|c|c|c|c|c|c|c|c|}
\hline \multirow[t]{2}{*}{ PCH-professional/parent } & \multirow[b]{2}{*}{$\mathrm{N}$} & \multirow[t]{2}{*}{ risk ${ }^{a} /$ risk } & \multirow[t]{2}{*}{$\mathrm{risk}^{\mathrm{a}} /$ protective } & \multirow[t]{2}{*}{ protective/risk } & \multirow[t]{2}{*}{ protective/protective } & \multirow[b]{2}{*}{ Agreement } & \multirow[b]{2}{*}{ Ppos } & \multirow[b]{2}{*}{ Pneg } \\
\hline & & & & & & & & \\
\hline \multicolumn{9}{|l|}{ Wellbeing of the child } \\
\hline ASQ-SE & 236 & 5 & 41 & 1 & 189 & $83 \%$ & .19 & .90 \\
\hline Cases/Controls & $82 / 154$ & $4 / 1$ & $36 / 5$ & $1 / 0$ & $41 / 148$ & $67 \% / 98 \%$ & $.18 / .29$ & $.69 / .98$ \\
\hline \multicolumn{9}{|l|}{ Competence of the parent } \\
\hline PSI & 250 & 22 & 32 & 21 & 175 & $68 \%$ & .45 & .87 \\
\hline Cases/Controls & $84 / 166$ & $19 / 3$ & $29 / 3$ & $9 / 12$ & $27 / 148$ & $58 \% / 59 \%$ & $.50 / .29$ & $.59 / .95$ \\
\hline PSOC & 247 & 14 & 41 & 10 & 182 & $70 \%$ & .35 & .88 \\
\hline Cases/Controls & $83 / 164$ & $14 / 0$ & $35 / 6$ & $5 / 5$ & $29 / 153$ & $59 \% / 48 \%$ & $.41 / .00$ & $.59 / .96$ \\
\hline PSBC & 254 & 14 & 41 & 21 & 178 & $61 \%$ & .31 & .85 \\
\hline Cases/ Controls & $85 / 169$ & $13 / 1$ & $36 / 5$ & $7 / 14$ & $29 / 149$ & $55 \% / 52 \%$ & $.38 / .10$ & $.57 / .94$ \\
\hline SF-12 mental & 254 & 23 & 32 & 22 & 177 & $68 \%$ & .46 & .87 \\
\hline Cases/Controls & $85 / 169$ & $19 / 4$ & $30 / 2$ & $10 / 12$ & $26 / 151$ & $56 \% / 62 \%$ & $.49 / .36$ & $.57 / .96$ \\
\hline SF-12 physical & 254 & 8 & 47 & 18 & 181 & $55 \%$ & .20 & .85 \\
\hline Cases/Controls & $85 / 169$ & $7 / 1$ & $42 / 5$ & $2 / 16$ & $34 / 147$ & $61 \% / 51 \%$ & $.24 / .09$ & $.61 / .93$ \\
\hline \multicolumn{9}{|l|}{ Role of the partner } \\
\hline FAD & 204 & 23 & 14 & 22 & 145 & $71 \%$ & .56 & .89 \\
\hline Cases/Controls & $72 / 132$ & $23 / 0$ & $12 / 2$ & $11 / 11$ & 26/ 119 & $68 \% / 49 \%$ & $.67 / .00$ & $.69 / .95$ \\
\hline PSI (partner) & 206 & 18 & 16 & 27 & 145 & $63 \%$ & .46 & .87 \\
\hline Cases/Controls & $69 / 137$ & $15 / 1$ & $17 / 1$ & $14 / 13$ & $23 / 122$ & $55 \% / 53 \%$ & $.49 / .13$ & $.60 / .95$ \\
\hline \multicolumn{9}{|l|}{ Social support } \\
\hline SSL received & 205 & 4 & 24 & 0 & 177 & $94 \%$ & .25 & .94 \\
\hline Cases/Controls & $71 / 134$ & $4 / 0$ & $20 / 4$ & $0 / 0$ & $47 / 130$ & $85 \% / 49 \%$ & 29./.00 & $.82 / .98$ \\
\hline SSL shortage & 205 & 15 & 13 & 20 & 157 & $65 \%$ & .48 & .90 \\
\hline Cases/Controls & $71 / 134$ & $13 / 2$ & $11 / 2$ & $11 / 9$ & $36 / 121$ & $65 \% / 58 \%$ & $.54 / .27$ & $.77 / .96$ \\
\hline Loneliness score & 205 & 14 & 14 & 13 & 164 & $72 \%$ & .51 & .92 \\
\hline Cases/Controls & $71 / 134$ & $12 / 2$ & $12 / 2$ & $5 / 8$ & $42 / 122$ & $74 \% / 59 \%$ & $.59 / .29$ & $.83 / .96$ \\
\hline Social & 205 & 10 & 18 & 9 & 168 & $71 \%$ & .43 & .93 \\
\hline Cases/Controls & $71 / 134$ & $9 / 1$ & $15 / 3$ & $4 / 5$ & $43 / 125$ & $72 \% / 57 \%$ & $.49 / .20$ & $.82 / .97$ \\
\hline Emotional & 205 & 14 & 14 & 16 & 161 & $69 \%$ & .48 & .91 \\
\hline Cases/Controls & $71 / 134$ & $12 / 2$ & $12 / 2$ & $7 / 9$ & $40 / 121$ & $70 \% / 58 \%$ & $.56 / .27$ & $.81 / .96$ \\
\hline \multicolumn{9}{|c|}{ Perceived barriers or life events within the care giving context } \\
\hline Deprivation questionnaire & 202 & 11 & 47 & 7 & 137 & $68 \%$ & .29 & .83 \\
\hline Cases/Controls & $63 / 139$ & $11 / 0$ & $37 / 10$ & $0 / 7$ & $15 / 122$ & $64 \% / 46 \%$ & $.37 / .00$ & $.45 / .93$ \\
\hline PSI (life events) & 203 & 3 & 55 & 3 & 142 & $61 \%$ & .09 & .83 \\
\hline Cases/Controls & $63 / 140$ & $3 / 0$ & $45 / 10$ & $0 / 3$ & $15 / 127$ & $63 \% / 46 \%$ & $.12 / .00$ & $.40 / .95$ \\
\hline
\end{tabular}

${ }^{\mathrm{a}}$ Consists of domains assessed as a risk or indistinct

PCH: Preventive Child Healthcare

Ppos: positive agreement (on the presence of risk factors)

Pneg: negative agreement (on the absence of risk factors, in this study indicating the presence of protective factors)

intense training in communication skills and more continuity of $\mathrm{PCH}$ professionals might contribute to parents' disclosure [24].

The domain Barriers or life events within the care-giving context contributed the most to the $\mathrm{PCH}$ professionals' overall assessment of being at risk. This corresponds with findings that, for example, poverty can be a risk for children's social-emotional development [5]. However, studies also show that not the type of risk factor, but the number of risk factors is most predictive for the outcome, e.g. 
Table 6 Contribution of domains to the overall assessment of the child by the PCH

\begin{tabular}{|c|c|c|c|}
\hline & $\begin{array}{l}\text { Cases (intervention based } \\
\text { on overall assessment) }\end{array}$ & $\begin{array}{l}\text { Controls (no intervention based } \\
\text { on overall assessment) }\end{array}$ & OR $(95 \% \mathrm{Cl})$ \\
\hline \multicolumn{4}{|c|}{ Wellbeing of the child } \\
\hline Risk or indistinct & $42(49.4 \%)$ & $6(3.7 \%)$ & \multirow[t]{2}{*}{$26.0(8.1-84.2)$} \\
\hline Protective & $43(50.6 \%)$ & $155(96.3 \%)$ & \\
\hline \multicolumn{4}{|c|}{ Competence of the parent } \\
\hline Risk or indistinct & $49(57.6 \%)$ & $6(3.6 \%)$ & \multirow[t]{2}{*}{$22.8(8.2-63.3)$} \\
\hline Protective & $36(42.4 \%)$ & $163(96.4 \%)$ & \\
\hline \multicolumn{4}{|l|}{ Role of the partner } \\
\hline Risk or indistinct & $40(51.9 \%)$ & $2(1.5 \%)$ & \multirow[t]{2}{*}{$61.7(8.5-450.6)$} \\
\hline Protective & $37(48.1 . \%)$ & $135(98.5 \%)$ & \\
\hline \multicolumn{4}{|l|}{ Social support } \\
\hline Risk or indistinct & $24(33.8 \%)$ & $4(3.0 \%)$ & \multirow[t]{2}{*}{$19.9(4.7-84.8)$} \\
\hline Protective & $47(66.2 \%)$ & $130(97.0 \%)$ & \\
\hline \multicolumn{4}{|c|}{ Barriers or life events within the care giving context } \\
\hline Risk or indistinct & $48(76.2 \%)$ & $10(7.1 \%)$ & \multirow[t]{2}{*}{101.1 (22.6- infinity) } \\
\hline Protective & $15(23.8 \%)$ & $130(92.9 \%)$ & \\
\hline
\end{tabular}

regarding child behavior [25]. This fits with our findings, since we found that whenever for participants two or more risk factors were assessed, they were more likely to be rated as a case.

\section{Strengths and limitations}

Strengths of our study are its high response rates and its embedding in routine care. Since more than $90 \%$ of all families with children are visiting $\mathrm{PCH}$ services, and participants did not differ greatly from parents who did not participate in our study, chances are high that a majority of the at-risk families was included as well. Moreover, to optimize the coverage of all domains of the familycentered approach, we used a number of well evaluated questionnaires.

Some limitations of our study should, however, be discussed. First, no perfect 'gold standards' were available for the domains of the family-centered approach, a fact which may decrease the validity as measured. Though the questionnaires provide a valuable representation of the domains of the family-centered approach, some questionnaires covered only certain aspects of a domain. Unfortunately, comparing specific questionnaires with specific questions taken from the family-centered approach was not feasible because of a lack of data on some questions.

Second, in this study, we looked only at the contents of the family-centered approach, i.e. the checklist with questions as mentioned in the Additional file 1: Appendix. That fits with a starting point of family-centered care that the family is the constant in the child's life. However, family-centered care is broader. Its relational component and participatory practices are of similar importance, as presented in Table 1 and in our description of the familycentered approach. In future research it would be interesting to assess what kinds of relational and participatory aspects of family-centered care are most essential to the identification of risk and protective factors, preferably including a stronger golden standard to define these aspects.

Third, we based our findings on single parent-reported questionnaires instead of using multi-informant and multi-method assessments. Fourth, we had to deal with missing values, although we imputed these in line with the principles of the family-centered approach.

\section{Conclusions}

Our findings partially support the validity of a familycentered approach in well-child care. The familycentered approach seems particularly useful to assess protective factors, but less useful for evaluating risk factors for infants' social-emotional development. For daily practice, one value of the family-centered approach lies in its assessment of protective factors, since building on strengths is recognized as important in optimizing children's wellbeing [26]. It is a systematic approach that could and should allow for individualized care. The family-centered approach seems promising to support the development of young children. 


\section{Additional file}

Additional file 1: Appendix 1 Overview of the contents of the familycentered approach; the five domains and corresponding questions. Appendix 1 contains an overview of the five domains of the familycentered approach and its corresponding questions. (DOCX $13 \mathrm{~kb}$ )

\section{Abbreviation}

PCH: Preventive Child Healthcare

\section{Acknowledgements}

Not applicable.

\section{Availability of data and materials}

The datasets during and/or analysed during the current study available from the corresponding author on reasonable request.

\section{Funding}

This study is funded by ZonMw, the Netherlands organisation for health research development (grant number: 157002010). ZonMw approved the design of the study, but had no role in the analyses and interpretation of data, in the writing of the manuscript, or in the decision to submit the manuscript for publication.

\section{Authors' contributions}

$\mathrm{MH}$ wrote the first draft and subsequently the revisions of the manuscript, coordinated the data collection, carried out the data analyses, and interpreted the data. AFW contributed to the design of the study, as well as interpretation of data analyses, supervised the data collection, and reviewed drafts of the manuscript. SAR designed the study, contributed to the interpretation of the data analyses, and reviewed and revised drafts of the manuscript critically. All authors are accountable for all aspects of the work in ensuring that questions related to the accuracy or integrity of any part of the work are appropriately investigated and resolved, and all authors approved the final manuscript as submitted.

\section{Competing interests}

The authors declare that they have no competing interests.

\section{Consent for publication}

Not applicable.

\section{Ethics approval and consent to participate}

The study was approved by the Medical Ethics Committee of the University Medical Center Groningen. All participants gave written informed consent at the start of the study, when their child was about 2 months old.

\section{Publisher's Note}

Springer Nature remains neutral with regard to jurisdictional claims in published maps and institutional affiliations.

Received: 12 February 2016 Accepted: 5 June 2017

Published online: 15 June 2017

\section{References}

1. Shonkoff JP, Garner AS. Committee on psychosocial aspects of child and family health, Committee on early childhood, adoption, and dependent care, section on developmental and behavioral pediatrics: the lifelong effects of early childhood adversity and toxic stress. Pediatrics. 2012; 129(1):e232-46.

2. Stewart-Brown SL, Schrader-McMillan A. Parenting for mental health: what does the evidence say we need to do? Report of Workpackage 2 of the DataPrev project. Health Promot Int. 2011;26(Suppl 1):i10-28.

3. George MR, Cummings EM, Davies PT. Positive aspects of fathering and mothering, and Children's attachment in kindergarten. Early Child Dev Care. 2010:180(1-2):107-19.

4. Cummings EM, Davies PT. Effects of marital conflict on children: recent advances and emerging themes in process-oriented research. J Child Psychol Psychiatry. 2002;43(1):31-63.
5. Spence SH, Najman JM, Bor W, O'Callaghan MJ, Williams GM. Maternal anxiety and depression, poverty and marital relationship factors during early childhood as predictors of anxiety and depressive symptoms in adolescence. J Child Psychol Psychiatry. 2002:43(4):457-69.

6. Morris AS, Silk JS, Steinberg L, Myers SS, Robinson LR. The role of the family context in the development of emotion regulation. Soc Dev. 2007:16(2):361-88.

7. Dunst CJ, Trivette CM. Meta-analytic structural equation modeling of the influences of family-centered care on parent and child psychological health. Int J Pediatr. 2009:2009:576840.

8. Green M, Palfrey JS. Bright Futures: Guidelines for Health Supervision of Infants, Children, and Adolescents (2nd ed., rev.). National Center for Education in Maternal and Child Health: Arlington, VA; 2002.

9. Committee on Hospital Care. American Academy of Pediatrics: family-centered care and the pediatrician's role. Pediatrics 2003, 112(3 Pt 1):691-697.

10. Tan NJ, Boom van den DC, Hermanns JJM: Protocol ter ondersteuning van de sociaal-emotionele ontwikkeling. Een volgsysteem voor consultatiebureau's (0-4 jarigen). Ontwikkeld in opdracht van DMO. [A protocol to enhance children's social-emotional wellbeing. A monitoring system for Preventive Child Healthcare ( $0-4$ years).]. University of Amsterdam. Faculty of social and behavioural sciences. Amsterdam; 2005.

11. Bronfenbrenner U, Ceci SJ. Nature-nurture reconceptualized in developmental perspective: a bioecological model. Psychol Rev. 1994;101(4):568-86.

12. Hielkema M, de Winter AF, de Meer G, Reijneveld SA. Effectiveness of a family-centered method for the early identification of social-emotional and behavioral problems in children: a quasi experimental study. BMC Public Health. 2011:11:636.

13. Hielkema M, De Winter AF, Feddema E, Stewart RE, Reijneveld SA. Impact of a family-centered approach on attunement of care and parents' disclosure of concerns: a quasi-experimental study. J Dev Behav Pediatr. 2014;35(4):292-300.

14. Sameroff AJ: Ecological perspectives on developmental risk. In WAIMH handbook of infant mental health groups at risk. 4th edition. Edited by Osofsky JD, Fitzgerald HE. New York: Wiley; 1999:223-248.

15. Hemphill JF. Interpreting the magnitudes of correlation coefficients. Am Psychol. 2003;58(1):78-9.

16. Borenstein M, Hedges L, Higgins J, Rothstein H. Introduction to meta-analysis Chicester. West Sussex, UK: John Wiley \& Sons; 2009.

17. Cohen J. A power primer. Psychol Bull. 1992;112(1):155-9.

18. Cicchetti DV, Feinstein AR. High agreement but low kappa: II. Resolving the paradoxes J Clin Epidemiol. 1990;43(6):551-8.

19. van Stel HF, Staal II, Hermanns JM, Schrijvers AJ: Validity and reliability of a structured interview for early detection and risk assessment of parenting and developmental problems in young children: a cross-sectional study. BMC Pediatr 2012, 12:71-2431-12-71.

20. Reijneveld SA, de Meer G, Wiefferink CH, Crone MR. Detection of child abuse by Dutch preventive child-healthcare doctors and nurses: has it changed? Child Abuse Negl. 2008;32(9):831-7.

21. Klein Velderman $M$, Crone MR, Wiefferink $C H$, Reijneveld SA. Identification and management of psychosocial problems among toddlers by preventive child health care professionals. Eur J Pub Health. 2010;20(3):332-8.

22. Honigfeld L, McKay K: Barriers to enhancing practice-based developmental services. J Dev Behav Pediatr 2006, 27(1 Suppl):S30-3; discussion S34-7, S50-2.

23. Carter AS, Briggs-Gowan MJ, Davis NO. Assessment of young children's social-emotional development and psychopathology: recent advances and recommendations for practice. J Child Psychol Psychiatry. 2004;45(1):109-34

24. Wissow LS, Roter DL, Wilson ME. Pediatrician interview style and mothers' disclosure of psychosocial issues. Pediatrics. 1994;93(2):289-95.

25. Appleyard K, Egeland B, van Dulmen MH, Sroufe LA. When more is not better: the role of cumulative risk in child behavior outcomes. J Child Psychol Psychiatry. 2005;46(3):235-45

26. Lamb-Parker F, LeBuffe P, Powell G, Halpern E. A strength-based, systemic mental health approach to support children's social and emotional development. Infants \& Young Children. 2008:21(1):45-55.

27. Squires J, Bricker D, Heo K, Twombly E. Identification of social-emotional problems in young children using a parent-completed screening measure. Early Childhood Research Quarterly. 2001;16(4):405-19.

28. Brock de AJLL, Vermulst AA, Gerris JRM, Abidin RR: NOSI-Nijmeegse Ouderlijke stress Index, Handleiding experimentele versie [NOSI-Nijmegen parenting stress Index, manual experimental version]. Lisse: Swets en Zeitlinger; 1992

29. Sanders MR, Woolley ML. The relationship between maternal self-efficacy and parenting practices: implications for parent training. Child Care Health Dev. 2005;31(1):65-73 
30. Ohan J. L., Leung DW, Johnston C: the parenting sense of competence scale: evidence of a stable factor structure and validity. Can J Behav Sci. 2000;32(4):251-61.

31. Jenkinson C, Layte $R$, Jenkinson D, Lawrence $K$, Petersen S, Paice C, et al. A shorter form health survey: can the SF-12 replicate results from the SF-36 in longitudinal studies? J Public Health Med. 1997;19(2):179-86.

32. Byles J, Byrne C, Boyle MH, Offord DR. Ontario child health study: reliability and validity of the general functioning subscale of the McMaster family assessment device. Fam Process. 1988;27(1):97-104.

33. Sonderen van E: Sociale Steun Lijst - Interacties en sociale Steun Lijst Discrepanties, een handleiding. [Social support list - Interactions and Social Support List - Discrepancies, a manual.]: Groningen: University of Groningen, Northern Centre for Healthcare Research; 1993.

34. De Jong J, van Tilbrg T: Manual of the loneliness scale [http://home.fsw.vu. nl/TG.van.Tilburg/manual_loneliness_scale_1999.html] (1999) Accessed 9 october 2016

35. Rots-de Vries de C: Rich evidence for poor families exploring the potential of pragmatic-driven intervention research in preventive child healthcare. Tilburg University, Arnhem; 2010.

\section{Submit your next manuscript to BioMed Central} and we will help you at every step:

- We accept pre-submission inquiries

- Our selector tool helps you to find the most relevant journal

- We provide round the clock customer support

- Convenient online submission

- Thorough peer review

- Inclusion in PubMed and all major indexing services

- Maximum visibility for your research

Submit your manuscript at www.biomedcentral.com/submit 